\title{
The analysis of unconscious action as a dangerous factor and the promotion of risk aversion action
}

\author{
G. Hotta ${ }^{1}$, M. Fukunaga ${ }^{1}$, Y. Ohbuchi ${ }^{2} \&$ H. Sakamoto ${ }^{3}$ \\ ${ }^{I}$ Department of Mechanical Engineering, \\ Ariake National College of Technology, Japan \\ ${ }^{2}$ Creative Engineering \& Design Education Center, \\ Kumamoto University, Japan \\ ${ }^{3}$ Graduate School of Science and Technology, \\ Kumamoto University, Japan
}

\begin{abstract}
Near accident data from chemical company safety division reports was analyzed with a view towards understanding workers' actions surrounding infrequent operations. It was found that 1) although workers received safety education, they were often injured or the cause of accidents. And 2) because workers often do not communicate with co-workers about workplace dangers, many patterns of accidents are repeated. An infrequent accident model was created to experimentally collect data about worker behavior to see if the situation was actually as implied above. The experimental data was then analyzed using Factor Analysis. The results showed that assumptions 1 and 2 had been correct and safety education recommendations are given to improve worker safety.

Keywords: near accident, infrequent operation, factor analysis, risk-taking, situations, psychological tests, risk reduction.
\end{abstract}

\section{Introduction}

This study investigates the issues of safety consciousness and risk-taking [1] of factory workers during infrequent operations [2]. The purpose of this study is to improve safety education. Infrequent operations are exemplified by repair of broken machinery. One feature of infrequent operations is that they don't have a 
service manual. Since there is no manual, the worker can work freely. However, this free work is often very dangerous. Figure 1 shows the rate of near accidents which occurred at a Japanese chemical company.

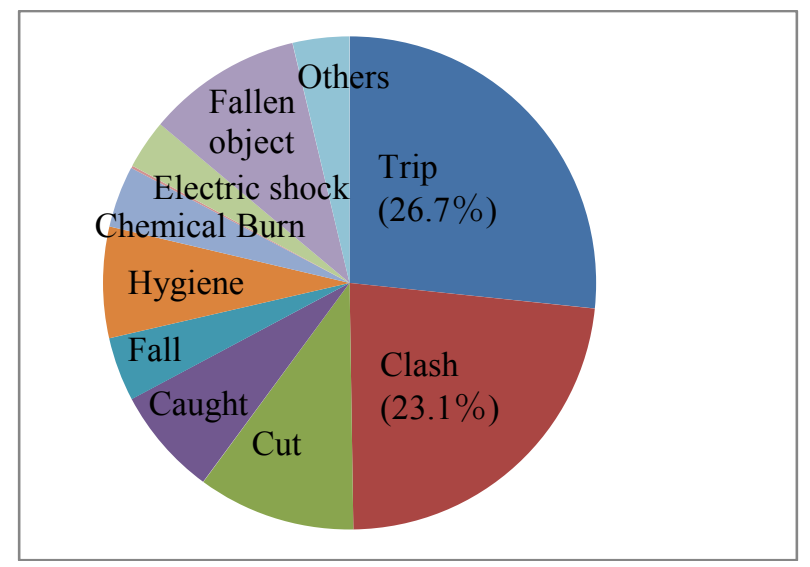

Figure 1: Integrated data of incidents in Muromachi Chemical Co.

A near accident is the experience where workers very nearly become injured. Most examples in fig. 1 have been generated during infrequent operations. We investigated more closely near accidents which happened at the chemical company. It was found that about $50 \%$ of near accident examples involved items almost falling onto the head or feet of workers and it was an unexpected sudden occurrence. Moreover, the same worker had sometimes repeatedly experienced the same kind of near accident. Furthermore, the worker had also experienced safety education at his company. According to Heinrich's Law, a near accident often develops into a true injury. The question we have to ask here is what should be done to ensure safety.

The worker is endowed with the capability to notice danger, and the capability to avoid danger, by birth. However, even if he notices danger, he may be tempted to take a risk. This is called risk taking and considered to be the cause of the near accident which occurs repeatedly. Moreover, if the near accident which he experienced is not told to others, the near accident of a place of work does not decrease. We consider four factors: risk cognition, risk aversion, risk taking, and risk communication, to be parameters which determine danger. And we decided to investigate how these four appear, when a worker encountered danger.

\section{Materials and methods}

\subsection{Workers' safety sense is investigated}

We conducted a further experiment to investigate risk cognition, risk aversion, and risk communication. Near accident data as reported by the chemical 
company showed tripping over obstacles on the floor and collisions with overhead obstacles to be of primary concern. So we tried to recreate these hazardous situations by purposely placing items in these positions and checking to see if workers recognized the hazards, avoided them, or communicated about them.

The subjects were 31 fourth graders of National College of Technology. The place of the experiment was a room made with an iron frame. The room was $1.0 \mathrm{~m}$ high $1.5 \mathrm{~m}$ wide, $5.0 \mathrm{~m}$ deep. There were pipes on the floor and steel frames protruded overhead. We considered these pipes and steel frames to be the source of danger both underfoot and overhead (see fig. 2).

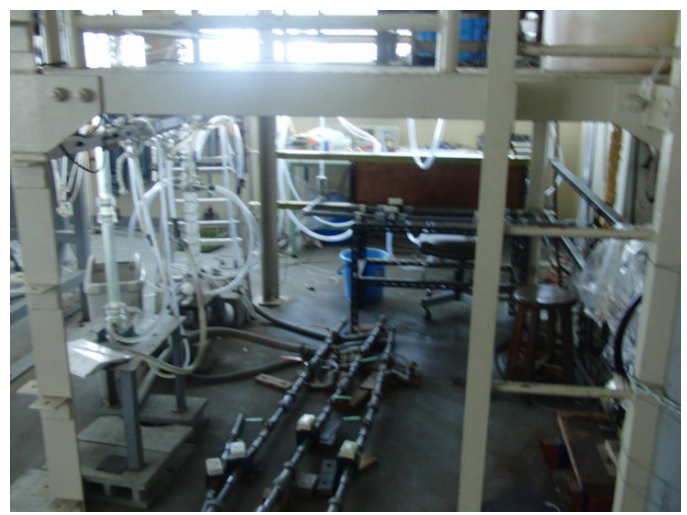

Figure 2: Dangerous mind companion test site place.

Students were asked to retrieve their attendance card from the room. We ordered the student to start from a position $3 \mathrm{~m}$ away from the room, and to get the card. We ordered them to hurry, and we timed them. In order to conduct an experiment on infrequent operations, neither cautions nor directions were given to them. The following questionnaire was conducted after the experiment.

(1) What were your thoughts before entering the room?

(2) What were your thoughts while you were in the room?

(3) What should be improved in order for other persons to participate in the experiment safely?

The purpose of question (1) is to investigate worker's risk cognition capability, and question (2) investigates worker's risk-aversion capability, and question (3) judged that investigation of a subject's risk-taking tendency was difficult. As a result, we considered another experiment which investigates a subject's risk-taking tendency.

\subsection{Workers' risk taking is investigated}

We decided to investigate when a worker takes risks. Therefore, we made the experimental equipment as shown in fig. 3. This experimental equipment has many push buttons, so the equipment is a design in which it is easy for a worker 

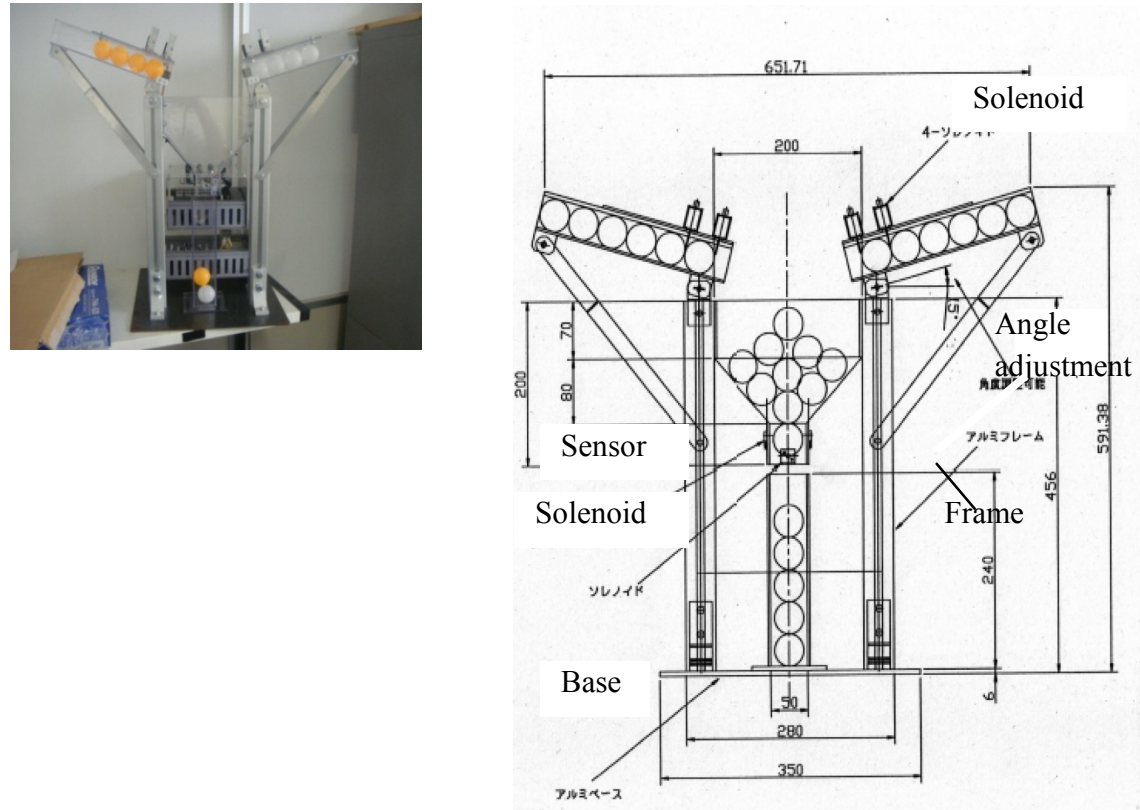

Figure 3: $\quad$ Risk reception experiment machine.

to make a mistake. We made easy work for the subject do, and measured their working time and the number of failures.

The subjects were 30 fourth graders of Ariake National College of Technology. White and red ping-pong balls were set at the right and left side of the experimental equipment. The subject pushes a button on a distribution power board that operates four gates in turn. As a result, a colored ball falls to a lower container. We indicated to the subject the order of the dropping balls, and made him put five balls into a container. However, we did not give directs about the best order for operating the gates, in order to conduct this experiment on infrequent operation.

The subject repeated the experiment 15 times. We judged it as a mistake, when two gates opened simultaneously, because all the balls would flow out. In that case, we directed that a ball would be returned to the subject and they might try again.

\section{Result and considerations}

\subsection{Workers' safety sense is investigated}

An accident like tripping over obstacles on the floor or collisions with overhead obstacles did not happen in the experiment. The questionnaire result is shown in fig. 4. 


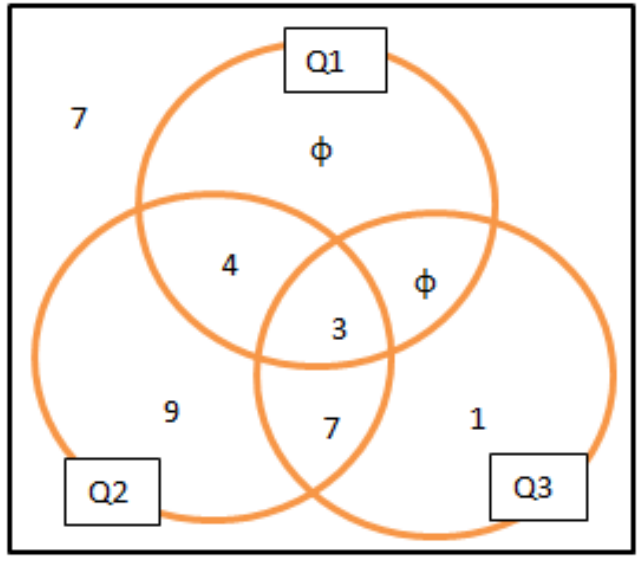

Figure 4: The result of a questionnaire.

This figure shows the number of replies about question (1) (risk cognition), question (2) (risk-aversion), and question (3) (risk communication). The number of replies to each question and the example of a reply are shown in table 1.

Table 1: $\quad$ The result of a questionnaire.

\begin{tabular}{|c|c|c|l|}
\hline Question & $\begin{array}{c}\text { Number of } \\
\text { replies }\end{array}$ & $\begin{array}{c}\text { Ratio } \\
(\%)\end{array}$ & \multicolumn{1}{|c|}{ Example of reply to a questionnaire } \\
\hline 1 & 7 & 17 & I checked the route on which we should walk. \\
\hline 2 & 23 & 56 & $\begin{array}{l}\text { I was careful of obstacles on the floor and } \\
\text { I walked while avoiding the obstacles }\end{array}$ \\
\hline 3 & 11 & 27 & $\begin{array}{l}\text { Obstacles of the passage should be } \\
\text { eliminated and workers should wear a } \\
\text { helmet. }\end{array}$ \\
\hline
\end{tabular}

According to fig. 4 and table 1 , about $50 \%$ of subjects' actions were risk aversion. $1 / 3$ of risk aversion was risk cognition and $1 / 2$ of risk aversion was risk communication. Among the subjects who demonstrated risk cognition, the subject which tells others of danger after having noticed the danger (risk communication) was 50\%. Moreover, $60 \%$ of subjects who showed risk cognition were also able to avoid risk. $25 \%$ of all subjects were not conscious of risk aversion during work. From the experiment, we found the following things: (1) It is difficult to recognize danger before working. (2) Subjects may not be conscious of risk aversion while working. (3) The dangerous information during work is not often communicated to others easily.

Forecasts of dangerous activities or near accident reports are performed as usual [3]. However, from the above considerations, for improvement of safety in factories, the following suggestions should be implemented: (1) Workers should 
be asked to analyze why they were not able to predict in advance the dangers at the time in an incident report; (2) Workers who are not conscious of danger should receive individual education in order to raise their consciousness of safety; (3) We should make the worker report their experiences of danger and their ideas about safety measures.

\subsection{Workers' risk taking is investigated}

The results for worker risk taking are shown in fig. 5. The graph in fig. 5 shows 3 different conditions (after 4 minutes time): mistakes, corrected mistakes, and improperly corrected mistakes (two or more balls are taken out simultaneously).

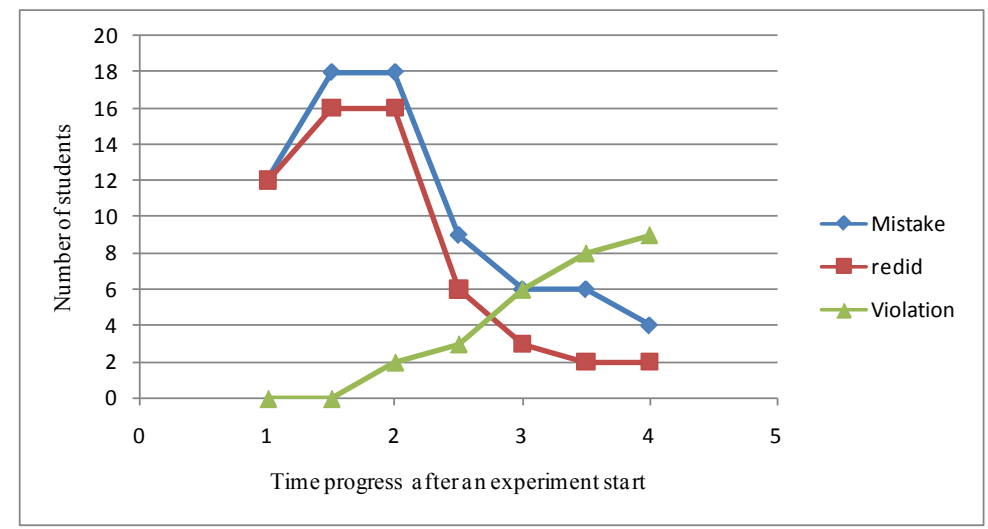

Figure 5: The result of the experiment investigating the tendency of risk taking.

According to fig. 5, the number of corrected mistakes decreases with time. Moreover, the subjects who redo by the right method after making a mistake also decrease their rate of mistakes. However, the rate of violation tends to increase, as time passes. From the result of this experiment, we got to know that subjects fall into two groups. They are the group which gives priority to risk aversion over time and the group which carries out risk taking in order to hurry.

\subsection{Correlation of Risk-taking intention and danger susceptibility}

In the results for risk-taking intention, we normalized the data of student's working times and work success rate. And we investigated mathematically the correlation between the experimental result for risk-taking intention and the questionnaire results which investigates workers' sense of safety. In this way, we made the correlation matrix [4] in Table 2.

From table 2, we are able to see that there was a tendency of the subjects with high success rates of work are also excellent in the quality of work, and the subjects which have long working times avoid risk. According to this correlation matrix, we could not find a clear correlation between danger susceptibility (result 
Table 2: Correlation matrix of risk-taking intention and danger perception capability.

\begin{tabular}{|l|c|c|c|c|c|}
\hline & $\begin{array}{c}\text { No } \\
\text { mistake }\end{array}$ & $\begin{array}{c}\text { Working } \\
\text { times }\end{array}$ & $\begin{array}{c}\text { Risk } \\
\text { cognition }\end{array}$ & $\begin{array}{c}\text { Near } \\
\text { accident }\end{array}$ & $\begin{array}{c}\text { Risk } \\
\text { communication }\end{array}$ \\
\hline No mistake & 1.000 & 0.504 & 0.329 & 0.217 & 0.092 \\
\hline Working times & 0.504 & 1.000 & 0.086 & -0.008 & 0.441 \\
\hline Risk cognition & 0.329 & 0.086 & 1.000 & 0.350 & 0.071 \\
\hline Near accident & 0.217 & -0.008 & 0.350 & 1.000 & 0.279 \\
\hline $\begin{array}{l}\text { Risk } \\
\text { communication }\end{array}$ & 0.092 & 0.441 & 0.071 & 0.279 & 1.000 \\
\hline
\end{tabular}

of a questionnaire), and risk-taking intention (shortness of working hours). The clearest correlation was seen between working hours and risk communication. We were not able to find a correlation between working hours and risk cognition capability or risk aversion capability. From the above considerations, we were not able to define a clear relation between risk cognition capability and riskaversion capability. This shows that risk cognition and risk aversion are different capabilities, and they are based on respectively different senses. Thus, in safety education, risk cognition capability and risk-aversion capability should be taught and trained by different methods. Furthermore, even if a worker experiences near accidents, his communication does not always raise others' safety. Furthermore, the curriculum of safety education needs to be purpose oriented, such as risk recognition, risk aversion, and risk communication.

\section{Conclusion}

To increase the safety measures of infrequent operations, and efficacy of safety education, we investigated worker's risk-taking intention and the relation of danger susceptibility (risk recognition, risk aversion, risk communication). As a result, we were not able to find clear correlations between risk-taking intention and danger susceptibility. This shows that even if a worker notices danger, he does not always avoid it. Therefore, in worker's safety education, in addition to training which predicts danger, it is necessary to carry out training which can help workers imagine methods of avoiding this predicted danger. Moreover, not only the worker that has recognized danger but also the worker who has avoided danger needs training which encourages them to tell others of their experience. Only after these education and training efforts are performed, can we expect an increase in the safety of infrequent operations.

\section{References}

[1] Kazumi Renge, Psychological Processes of Risk-taking behavior in driving and New Approach toward Promoting Risk-Avoiding Behavior. International Association of Traffic and Safety Sciences, Vol. 26. No.1, pp. 12-14, 2000. 
[2] Chikashi Oozeki, All the new safety controls 3rd edition, Japan Industrial Safety and Health Assoc, pp. 764-768, 2005.

[3] Jonah, B.A., Accident risk and risk-taking behavior among young drivers, Accident Analysis and Prevention, Vol. 18, No. 4, pp. 225-271,1986.

[4] Toshiro Terano, A guide to system engineering, Kyoritsu Shuppan CO., LTD, pp. 80-93, 1996. 